\title{
Beliefs And The Situated Nature of Self- Handicapping: Promoting Growth Intelligence Mindset Beliefs Reduces Behavioral Self- Handicapping
}

Lilla Török ( $\nabla$ torok@tf.hu )

ULR 7369 -URePSSS - Unité de Recherche Pluridisciplinaire Sport Santé Société

\section{Zsolt Péter Szabó}

Budapest University of Technology and Economics

\section{Gábor Orosz}

ULR 7369 -URePSSS - Unité de Recherche Pluridisciplinaire Sport Santé Société

\section{Research Article}

Keywords: Self-Handicapping, Theory of Intelligence, Intelligence Mindset

Posted Date: February 7th, 2022

DOI: https://doi.org/10.21203/rs.3.rs-1307044/v1

License: (c) (1) This work is licensed under a Creative Commons Attribution 4.0 International License.

Read Full License 


\section{Abstract}

The present study examined the interplay between chronic intelligence beliefs, manipulated intelligence beliefs and self-handicapping processes. Prior studies showed that holding fixed intelligence theory makes one vulnerable to resorting to self-protective mechanisms such as self-handicapping, while growth intelligence mindset can serve as a protective factor for self-handicapping. However, no prior studies have examined the potential interaction between pre-experimental intelligence beliefs, the manipulation of intelligence mindsets and behavioral self-handicapping. Although in our student sample $(N=101)$ there was no main effect of the mindset manipulations, participants with an initial fixed mindset benefited a lot from a brief growth mindset manipulation and displayed the lowest levels of behavioral selfhandicapping. The mindset manipulation had less effect on self-handicapping of originally growthmindset individuals. These laboratory results demonstrate the benefits of growth mindset triggers which can be especially beneficial to reduce self-handicapping of young adults with a fixed mindset in educational settings.

\section{Introduction}

As an educator one may ask what sort of beliefs can promote or undermine their students' selfhandicapping. At school, beliefs about intellectual capacities can become easily triggered by various situations. Students may think that they can alter their intellectual capacities, or they might think that it is something they cannot change. Prior studies demonstrated that if one thinks their intellectual capacities can be improved, it will lead to less maladaptive behaviors such as self-handicapping [e.g., ${ }^{1}$. However, in this field, these theoretically reasonable links were mainly supported by correlational results without manipulating students' beliefs about their intelligence. The present behavioral study aims to fill this gap with both considering students' chronic intelligence beliefs as well as manipulating students' mindset beliefs through specific triggers and also using a behavioral measure of self-handicapping.

\section{Self-handicapping in education}

Self-worth theory ${ }^{2,3}$ assumes that the goal to achieve the sense of competency, respect and selfacceptance are the most important human needs. In school, this feeling of worthiness frequently depends on academic achievement. If this is the case, students struggle to avoid failure thus seeming to be incompetent, instead they are concerned with appearing able and worthy in front of their peers. Indeed, Covington and Omelich ${ }^{4}$ found among students that reputation of being exceptionally smart was the most important contributor to feelings of personal well-being, far more relevant than the GPA. Among other behaviors, self-handicapping can be a suitable tool to preserve and protect self-esteem in such academic situations ${ }^{5}$. In these cases, students do not exert effort, postpone studying until the last moment or attend in performance-inhibiting activities (e.g., going out before an important performance situation), so subsequent failure may be attributed to non-ability, rather unstable, controllable, and specific causes. Such handicaps, erected by students themselves, allow them to draw attention to other factors than low ability in case of failure, thus minimizing the impact of failure on their self-image and 
protecting self-esteem. In other words, self-handicapping represents attempts to control attributions about the self and also the implications for self-esteem of anticipated or potential failure by establishing a non-ability explanation for its cause ${ }^{6,7}$. Self-handicapping occurs when the individual's self-concept is under threat, and the uncertainty about one's ability is high ${ }^{8}$. Likewise, these attributions are beneficial because they support sustaining the motivation and positive emotions in case of either failure or success $^{9}$. Self-handicapping is grounded in attributions of abilities and therefore the perception of the nature of abilities matters. More specifically, they can be considered as stable and also as malleable characteristics and this is where Dweck's [see ${ }^{10}$ ] mindset theory becomes relevant.

\section{Intelligence beliefs}

Different views about intelligence are thought to have a profound effect on the way people interpret their performance ${ }^{11,12}$. Previous research has demonstrated that people can have one of two implicit theories or mindsets ${ }^{13}$. Those holding an entity theory or fixed mindset believe that skills and abilities are fixed and relatively stable qualities ${ }^{13}$, and their explanations regarding achievement settings also reflect these theories ${ }^{14}$. Accordingly, they likely adopt performance goals focusing on demonstrating their abilities and searching for positive evaluations from others ${ }^{13}$. However, those with an incremental theory or growth mindset believe that abilities and skills are malleable or changeable. Individuals who hold a growth mindset believe that these characteristics can be improved with exerting effort (also with others' support and good strategy). People with growth mindset are likely to adopt learning goals, choose challenging tasks, and employ adaptive strategies to improve their abilities ${ }^{13}$. Research in achievement contexts such as academics ${ }^{15}$, physical education and sport ${ }^{16,17}$ demonstrated that the performer's adaptive involvement, affect, cognition and performance are guided by these implicit theories of ability.

Specifically, in the academic context, implicit theories about intelligence have been widely examined ${ }^{18,19}$. It was found that implicit theories can create distinct meaning systems ${ }^{12,14}$ that can trigger different patterns of response to challenging academic situations and setbacks ${ }^{13,20}$ and ultimately influencing students' learning processes and achievement ${ }^{15}$.

\section{Self-handicapping and intelligence beliefs in education}

Given the attributional foundations of self-handicapping, implicit beliefs about intelligence have been identified as a potential predictor of self-handicapping. Based on the mindset theory, those students who think that their intellectual abilities are stable do not invest energy in self-development (since it is not possible) but strive to show their abilities in front of others and put themselves in the most favorable light possible. Beliefs in fixed ability lead to a threatening interpretation of failure in terms of "being dumb and remaining dumb". For this reason, students with a fixed mindset are more likely to engage in selfhandicapping than those who regard their abilities as changeable since these individuals strive to develop and improve rather than protect themselves ${ }^{21}$.

Prior studies found significant relationships between implicit theories of ability and self-handicapping across various domains [e.g., ${ }^{1,22}$. For example, in an early correlational study ${ }^{1}$ proposed that high trait 
self-handicapper students are more likely to endorse the entity view of abilities (composite score for athletic ability, intelligence and social skills), than their low trait self-handicapping peers [see also ${ }^{23}$ ]. Likewise, in sports settings, entity beliefs positively associated with self-reported effort reducing and selfreported excuse making, while incremental beliefs negatively associated with self-reported effort reducing 24. Similar results were found in physical educational contexts, where self-reported inclination to selfhandicapping showed similar pattern to implicit ability beliefs ${ }^{22,25}$. De Castella and Byrne ${ }^{26}$ also found that self-referenced theories about abilities (e.g., "in fact, / cannot really change how intelligent / am") are better predictors of self-reported motivation, performance as well as academic self-handicapping than general implicit theories (e.g., "in fact, you cannot really change how intelligent you are").

Only a handful of studies investigated such a relationship using behavioral measures. According to Niiya et al. ${ }^{27}$ participants primed with the entity theory practiced less IQ test items (behavioral selfhandicapping) than those primed with the incremental theory. Similarly, following a failure experience, participants who had been listening to an entity message about giftedness engaged in behavioral selfhandicapping to a greater degree than those who had been exposed to an incremental message about giftedness $^{28}$. In a study of Rickert et al. ${ }^{29}$ the strength of one's entity theory of intelligence was positively associated with self-reports of academic self-handicapping and was negatively associated with selfreported study time and effort measured by daily records.

Since the majority of prior studies examined the link between implicit theory of intelligence and selfhandicapping with self-reported methods, the causal link between the two constructs might require further investigations through lab experiments. Furthermore, little is known not only about how experimentally altered mindsets can change self-handicapping, but also about the interactive effects of pre-experimental (chronic) mindsets and the experimentally manipulated mindsets on self-handicapping. More specifically, no prior studies examined whether an initially fixed vs. growth mindset student can profit more from a growth mindset intervention if we focus on their self-handicapping behaviors. The present study aims to investigate these two research questions with a laboratory experiment.

\section{Methods}

\section{Participants}

Similarly to earlier laboratory studies ${ }^{27,28}$, we aimed to collect data from about 110 students. In the present work, participants were male university students $(\mathrm{N}=105)$, as based on prior studies [e.g., ${ }^{30}$ ] males use more behavioral self-handicapping than females. Four participants were dropped from the analyses due to expressing general suspicion of the deception utilized in the study, resulting in a final sample of 101 participants. Statistical analyses were conducted on this final sample. The participants were between 18 and 55 years of age $\left(M_{\text {age }}=27.33\right.$ years, $S D_{\text {age }}=8.79$ years $)$. Participants received partial course credit for their participation. The study was conducted in accordance with the Declaration of Helsinki and with 
the approval of the local university's ethical committee as well as the informed consents of the participants.

\section{Procedure}

The research procedure is shown in Figure 1. Participants were told that they can contribute to the validation of an online IQ test based on its reliable offline version.

1. Preliminary survey. First, they completed an online survey with items related to their intelligence beliefs and socio-demographic characteristics (see below in details). Two or three days later they were invited to the laboratory to participate in an experiment. The behavioral data were collected individually in a small university laboratory in which participants were randomly assigned to one of the two experimental conditions: (a) entity, (b) incremental mindset.

2. Manipulation of intelligence mindsets: Upon arrival at the laboratory participants had to wait for a few minutes in the corridor, where scientific posters illustrated with pictures and diagrams were pinned on the wall either about the heritability of the intellectual skills (entity condition), or the malleability of the brain (incremental condition). Then participants were greeted by the experimenter wearing white lab coat who accompanied them to the laboratory room. Next, the experimenter delivered the implicit message manipulation. In the entity condition, participants were told the following:

In this research intellectual skills are investigated. As you must know, intelligence is defined by an IQ score. When a baby is born, they already possess a particular intellectual potential that is unfolding throughout their life. This means that our intellectual skills are barely changeable, instead they predominantly remain stable and fixed through the lifespan. Hence, we are not able to do anything to change our intellectual skills. This research (the experimenter points to the same scientific report pinned on the wall that they had seen before) for instance is significant for this reason. Thompson and his colleagues studied identical twins in 2002. Identical twins are known to be $100 \%$ identical in terms of their DNA. The authors found that intellectual skills are $88 \%$ identical in the two siblings. This means that intellectual skills are highly determined by our genes. This is the reason behind the intelligence not changing throughout our lifespan.

In the incremental condition, participants were told the following:

In this research intellectual skills are investigated. Numerous previous studies showed that our intellectual skills change through the lifespan. This process depends on how much we learn and the amount of effort we exert. So, the scientific reports from the last few years evidently showed us that the structure of the brain develops and changes when we work hard on a task or exert great intellectual effort. As a result, new brain connections form and the existing connections strengthen. As such, human brain and intellectual skills can be developed. This research (the experimenter points to the same scientific report pinned on the wall that they had seen before) for instance is significant for this reason. Zatorre and 
his colleagues studied ordinary people learning to juggle in 2013. They found that after just one week of learning participants' gray matter density increased, demonstrating development of their brains. This is the reason behind the statement that intellectual skills can be cultivated.

Both conditions additionally heard some statements about the importance of the intelligence:

Nonetheless we all know that intelligence is a crucial attribute of ourselves. Intelligence affects the grades we receive, the university and the job we get into, so basically and ultimately how successful we will be in our lives. Thus, intelligence is really an important factor.

3. Intelligence test exercise: Subsequently, participants were conseed that they would be exposed to some "trial" items before the "real" IQ test in order to assure that they understood the task and were familiar with the type of it. Participants were told that confounding factors such as misunderstanding needs to be ruled out so the real IQ test score would reflect their real intellectual skills. Six items were selected from the Raven Progressive Matrices ${ }^{31}$ and the last four were modified to be unsolvable. Participants had six minutes to complete the tasks and they were informed about the status of the countdown. After the 6th minute the experimenter took the sheet, and visibly flipped through it.

4. Behavioral measure of self-handicapping: Then participants were informed that the validation process needs to be explored in various circumstances. One of these circumstances is related to the effect of music on their performance. Therefore, the experimenter asked the participants to choose one of the available CDs to listen to while completing the IQ test ${ }^{27,32}$. According to the cover story, the music on each CD has a different effect on their cognitive functions. The CDs were stacked horizontally (so that the colored labels could be easily seen) in a CD rack and labelled: with Three green dots "Highly Enhancing" (1), Two green dots "Moderately Enhancing" (2), One green dot "Mildly Enhancing" (3) without a sign "Neutral" (4), One red dot "Mildly Detracting" (5), Two red dots "Moderately Detracting" (6) and Three red dots "Highly Detracting" (7) effects. The experimenter emphasized that the data collection is about to finish so there were enough music choices from all types. Therefore, they are free to choose whatever they really wish to listen to. Participants were left alone for one minute, then handed the selected CD to the experimenter.

5. Manipulation and suspicious checks: While the experimenter allegedly started to mount the music device, participants were requested to answer some manipulation checks regarding their $\mathrm{CD}$ choice ("What kind of effect the red/green signed music has on the cognitive functions?") and intelligence mindset (two items, see below). The potential suspicious effects were also tested using a funnel method $^{33}$. First, participants were asked, "How could you describe the purpose of this study in your own words?". Then, they were asked whether they had noticed anything particular during the experiment and especially during the practice session.

6. Debriefing. Finally, all participants were thoroughly debriefed directly following the study completion and dismissed. 


\section{Measures}

Pre-and post-manipulation intelligence mindset beliefs. Students' implicit theories of intelligence were assessed by the Theories of Intelligence Scale ${ }^{13}$. The scale is composed of two four-item subscales of the entity (e.g., "Your intelligence is something about you that you can't change very much"; Cronbach's a $=0.91$ ) and incremental theories (e.g., "No matter who you are, you can significantly change your intelligence level'; Cronbach's $a=0.92$ ) resulting in a unidimensional measure (Cronbach's $a=0.93)$. The two subscales were interrelated $(r=-0.73, p<0.001)$. Respondents indicated their answers on a six-point Likert scale. All eight items were used pre-manipulation, and two seminal items ("You have a certain amount of intelligence, and you can't really do much to change it" and "You can always substantially change how intelligent you are") of the scale were used post-manipulation as manipulation checks $\left(r_{\text {inter- }}\right.$ item $=0.68 ; p<0.001)$. The items on the pre- and post-treatment measures were averaged (separately) such that higher values correspond to more growth mindsets.

Importance of intelligence. Participants were asked about the importance of the domain that was about to be threatened: "How important is the level of your intelligence to you?". The statement was rated on a 4-point Likert scale from not at all (1) to very much (5).

Behavioral self-handicapping measure. Self-handicapping behavior was operationalized as choosing suboptimal circumstances for performing the target intelligence task. Therefore, prior to taking the second test of intellectual ability, each participant had the opportunity to select one sort of music they wanted to listen to during the IQ test. The music selection ranged on a scale with values from 1 (highly enhancing) to 7 (highly detracting). The middle of the scale was represented by neutral music. The CD choice constituted the self-handicapping behavior. Based on prior literature we used it as a continuous measure as not choosing the most optimal condition (1-highly enhancing) can be interpreted as selfhandicapping. Demographic data. Finally, demographic characteristics of participants were asked: gender, age, and whether their intellectual skills had been measured before.

\section{Statistical Analyses}

Statistical analyses and data visualization were performed with IBM SPSS software version 22.0 and R 4.0.3 $3^{34}$. Within $\mathrm{R}$, the tidyverse ${ }^{35}$, the ggplot $2^{36}$, packages were used for data transformation and visualization. First, we checked potential differences between the control and experimental groups in terms of age, prior intelligence mindset, importance of intelligence, prior participation in intelligence testing and found no differences between the two groups (all $p s>0.58$ ). Second, we treated the CD choice behavioral self-handicapping variable as a continuous measure, ordinary least squares (OLS) regression analysis was performed to examine the effect of the experimental manipulation (fixed vs. growth mindset) as well as the interaction between the experimental manipulation and the prior intelligence mindsets. The pre-experimental growth intelligence mindset, the intelligence mindset manipulation and their interaction were included in the regression model. 


\section{Results}

\section{Manipulation checks}

All 101 participants responded correctly to the self-handicapping manipulation check question and understood the meaning of the CD color signs. For the participants, the level of intelligence was an important personal characteristic (the lowest score was 3 of a 5 -point scale, $M=3.65, S D=0.48$ ). We also found a significant difference between the two conditions in terms of their post-manipulation growth intelligence mindsets, $t(99)=-8.40, p<0.001, d=1.67\left(M_{\text {growth }}=4.72, S D_{\text {growth }}=0.81 ; M_{\text {fixed }}=3.13\right.$, $S D_{\text {fixed }}=1.07$ ).

\section{The effect of (pre-manipulation and manipulated) intelligence mindset on behavioral self-handicapping}

Our first research question was related to the main effect of the fixed vs. growth mindset manipulation on self-handicapping behavior. Even though participants in the fixed mindset condition $(M=4.30, S D=2.34)$ made more self-handicapping decisions numerically, than participants in the growth mindset condition $(M=4.96, S D=2.27)$, there was no significant difference between the two groups, $t(99)=-1.44, p=0.15$. The interaction between pre-experimental intelligence mindset and intelligence mindset manipulation was significant concerning self-handicapping behavior, $\mathrm{b}=-1.21, t(1,97)=-2.709, p=0.008, d=0.52$.

As displayed on Figure 2, the experimental manipulation made a great difference among people with an initially fixed mindset. Participants with pre-experimental fixed intelligence mindset and participating in the fixed mindset condition performed the highest level of self-handicapping. However, participants with similar pre-experimental fixed mindset in the incremental experimental condition performed much less self-handicapping behavior. The experimental manipulations made a less salient difference among students with an initial growth intelligence mindset.

Figure 2.

More specifically, among students with one standard deviation below the mean of pre-experimental mindset (towards the fixed direction) the difference between the two experimental conditions was significant, $\mathrm{b}=1.89, t(1,97)=3.009, p=0.003, d=0.81$. However, there was no significant difference in the two conditions among initially growth mindset students (one standard deviation from the mean towards the growth mindset side on the continuum), $\mathrm{b}=-0.52, t(1,97)=-0.831, p=0.41, d=0.23$. In sum, if we compare the effects of the experimental manipulations, it appears that the effect of the manipulation is contrasting the prior mindsets of participants. However, while it resulted in a non-significant increase of self-handicapping among initially growth-mindset individuals, it had an almost four times larger, strongly significant and benevolent effect on the initially fixed mindset participants.

\section{Discussion}


According to the prior literature, only one experiment examined how manipulated intelligence mindsets can influence behavior self-handicapping ${ }^{27}$ and found that manipulated fixed mindset leads to elevated self-handicapping (in contrast to manipulated growth mindset). Furthermore, two experiments examined the role of pre-existing mindsets on self-handicapping ${ }^{28,29}$ showing that fixed mindset is associated with an elevated level of self-handicapping. The present study aimed to consider both pre-experimental and manipulated intelligence mindsets in self-handicapping. In this study, we were able to replicate existing findings, but also to extend them to demonstrate how these associations are influenced by prior intelligence mindsets.

We were interested in who might profit more from a growth mindset induction: those who have prior congruent beliefs (pre-experimental growth mindset) or those who "need" it more as they have incongruent pre-experimental fixed mindset beliefs. Based on the results, the second hypothesis is confirmed. It appears that initially fixed mindset students could benefit more from the growth mindset manipulation in terms of reduced self-handicapping (in contrast to initially growth mindset students).

More specifically, students who reported an initially fixed mindset and received an experimental growth mindset induction chose less distracting music than the initially fixed mindset students in the fixed mindset-promoting experimental condition. The difference among growth mindset students after the experimental manipulation was visibly less salient. These results are in line with the above-mentioned studies $^{27-29}$ in which growth mindset appears as a protecting shield against self-handicapping. The present results not only confirm these results, but also show that even a five-minute brief mindset induction can make a salient difference in the self-handicapping behavior of the vulnerable, fixed mindset students, while such manipulation had less impact on those students who are protected by prior growth mindset. Additionally, these results are in line with assumptions of Schwinger et al. ${ }^{37}$ showing the effectiveness of even a very brief emotional-motivational manipulation that could reduce the level of selfhandicapping.

Self-handicapping can serve as a good excuse in situations with a high risk of failure. However, the need to have and use this excuse can be related to the perceived stakes of the situation that are different for fixed vs. growth mindset students. For fixed mindset students, the stakes are high as the threat is related to them being "dumb" in an essential, unchangeable manner, and therefore they have a strong affordance to use self-handicapping. However, the stakes and the related threat are smaller for the growth mindset students (for whom failing is part of the learning process) leading to less self-handicapping ${ }^{21}$.

The present study is not without limitations. First, the procedure was tailored to in-person laboratory situations that can allow identifying causal relationships. However, unfortunately, the pandemic did not enable us to collect a larger sample size. Although our sample size was similar to earlier experimental studies $^{27,28}$, the current results still appear to be somewhat underpowered. Second, our purpose was to mimic a believable, behavior-based, threatening situation with high ecological validity in which there is an offline performance embedded in an interaction with the experimenter. However, the presence of a whitecoated experimenter that created such experimental effects (instead of a unitary online experience) might 
have led to some inconsistency between participants. Third, behavioral self-handicapping has been conceptualized as choosing a suboptimal context that can reduce their performance [e.g., ${ }^{27}$ ] thus other manifestations of behavioral self-handicapping were not investigated. It is important to state that the present one is a preliminary study. Building on its weaknesses, future studies should consider the abovementioned limitations when investigating experiments or programs that aim to reduce self-handicapping with changing mindset beliefs. For example, as successful intervention programs are available, future studies might investigate the role of growth mindset interventions [e.g., ${ }^{15}$ ] in long term changes in selfhandicapping behaviors.

\section{Declarations}

\section{Acknowledgement}

We thank to Kata Sik (University of Vienna) and Dr. Tamás Nagy (Eötvös Loránd University) for their assistance and comments in the data analyses and visualization process. We are also thankful for the financial support of the STARS, Hauts de France and the DSG2, Mind|ful|set Grants.

\section{Data availability}

The datasets generated and/or analyzed during the current study are available from the corresponding author on request.

\section{References}

1. Rhodewalt, F. Conceptions of Ability, Achievement Goals, and Individual Differences in SelfHandicapping Behavior: On the Application of Implicit Theories. Journal of Personality $62,67-85$ (1994).

2. Covington, M. Self-worth and the fear of failure. in Making the Grade 72-103 (Cambridge University Press, 1992).

3. Covington, M. Self-worth theory: Retrospection and prospects. in Educational Psychology Handbook Series. Handbook of Motivation at School (eds. Wenzel, K. R. \& Wigfield, A.) 141-169 (Routledge/Taylor \& Francis Group, 2009).

4. Covington, M. \& Omelich, C. L. Controversies or consistencies? A reply to Brown and Weiner. Journal of Educational Psychology 76, 159-168 (1984).

5. Hendrix, K. S. \& Hirt, E. R. Stressed out over possible failure: The role of regulatory fit on claimed selfhandicapping. Journal of Experimental Social Psychology 45, 51-59 (2009).

6. Jones, E. E. \& Berglas, S. Control of Attributions about the Self Through Self-handicapping Strategies: The Appeal of Alcohol and the Role of Underachievement. Personality and Social Psychology Bulletin 4, 200-206 (1978). 
7. Rhodewalt, F. Self-Handicapping: On the Self-Perpetuating Nature of Defensive Behavior. Social and Personality Psychology Compass 2, 1255-1268 (2008).

8. Kim, Y.-H., Chiu, C. \& Zou, Z. Know thyself: Misperceptions of actual performance undermine achievement motivation, future performance, and subjective well-being. Journal of Personality and Social Psychology 99, 395-409 (2010).

9. Weiner, B. An Attributional Theory of Achievement Motivation and Emotion. Psychological Review 92, 548-573 (1985).

10. Dweck, C. S. \& Yeager, D. S. Mindsets: A View From Two Eras. Perspectives on Psychological Science 14, 481-496 (2019).

11. Molden, D. C. \& Dweck, C. S. Finding "meaning" in psychology: A lay theories approach to selfregulation, social perception, and social development. American Psychologist 61, 192-203 (2006).

12. Dweck, C. S. \& Molden, D. C. Mindsets: Their impact on competence motivation and acquisition. in Handbook of Competence and Motivation: Theory and Application (eds. Elliot, A. J., Dweck, C. S. \& Yeager, D. S.) 135-154 (The Guilford Press, 2017).

13. Dweck, C. S. Self-Theories: Their Role in Motivation, Personality, and Development. Essays in Social Psychology. undefined (Psychology Press, 1999).

14. Hong, Y. Y., Dweck, C. S., Chiu, C. Y., Lin, D. M. S. \& Wan, W. Implicit theories, attributions, and coping: A meaning system approach. Journal of Personality and Social Psychology 77, 588-599 (1999).

15. Yeager, D. S. et al. A national experiment reveals where a growth mindset improves achievement. Nature 573, 364-369 (2019).

16. Vella, S. A., Braithewaite, R. E., Gardner, L. A. \& Spray, C. M. A systematic review and meta-analysis of implicit theory research in sport, physical activity, and physical education. International Review of Sport and Exercise Psychology 9, 191-214 (2016).

17. Ommundsen, Y. Implicit Theories of Ability and Self-regulation Strategies in Physical Education Classes. Educational Psychology 23, 141-157 (2003).

18. Costa, A. \& Faria, L. Implicit theories of intelligence and academic achievement: A meta-analytic review. Frontiers in Psychology vol. 9829 (2018).

19. Dweck, C. \& Yeager, D. A Growth Mindset about Intelligence. in Handbook of Wise Interventions: How Social Psychology Can Help People Change (eds. Walton, G. \& Crum, A.) 9-35 (Guilford Press, 2020).

20. Dweck, C. S. \& Leggett, E. L. A Social-Cognitive Approach to Motivation and Personality. Psychological Review 95, 256-273 (1988).

21. Török, L., Szabó, Z. P. \& Tóth, L. A critical review of the literature on academic self-handicapping: theory, manifestations, prevention and measurement. Social Psychology of Education 21, 11751202 (2018).

22. Ommundsen, Y. Self-handicapping strategies in physical education classes: the influence of implicit theories of the nature of ability and achievement goal orientations. Psychology of Sport and Exercise 2, 139-156 (2001). 
23. Shih, S.-S. Perfectionism, Implicit Theories of Intelligence, and Taiwanese Eighth-Grade Students' Academic Engagement. The Journal of Educational Research 104, 131-142 (2011).

24. Chen, L. H. et al. Implicit theory of athletic ability and self-handicapping in college students. Psychological Reports 103, 476-484 (2008).

25. Ommundsen, Y., Haugen, R. \& Lund, T. Academic self-concept, implicit theories of ability, and selfregulation strategies. Scandinavian Journal of Educational Research vol. 49 461-474 (2005).

26. de Castella, K. \& Byrne, D. My intelligence may be more malleable than yours: the revised implicit theories of intelligence (self-theory) scale is a better predictor of achievement, motivation, and student disengagement. European Journal of Psychology of Education 30, 245-267 (2015).

27. Niiya, Y., Brook, A. T. \& Crocker, J. Contingent self-worth and self-handicapping: Do incremental theorists protect self-esteem? Self and Identity 9, 276-297 (2010).

28. Snyder, K. E., Malin, J. L., Dent, A. L. \& Linnenbrink-Garcia, L. The message matters: The role of implicit beliefs about giftedness and failure experiences in academic self-handicapping. Journal of Educational Psychology 106, 230-241 (2014).

29. Rickert, N. P., Meras, I. L. \& Witkow, M. R. Theories of intelligence and students' daily selfhandicapping behaviors. Learning and Individual Differences 36, 1-8 (2014).

30. Hirt, E. R. \& McCrea, S. M. Man smart, woman smarter getting to the root of gender differences in self-handicapping. Social and Personality Psychology Compass 3, 260-274 (2009).

31. Raven, J., Raven, J. C. \& Court, J. H. Manual for Raven's progressive matrices and vocabulary scales. Section 1: General overview. (Harcourt Assessment, 2003).

32. Rhodewalt, F. \& Davison, J. Self-Handicapping and Subsequent Performance: Role of Outcome Valence and Attributional Certainty. Basic and Applied Social Psychology 7, 307-322 (1986).

33. Bargh, J. A. \& Chartrand, T. L. The mind in the middle: A practical guide to priming and automaticity research. in Handbook of Research Methods in Social and Personality Psychology (eds. H. T. Reis \& C. M. Judd) 253-285 (Cambridge University Press, 2000).

34. R Core Team. R: A Language and Environment for Statistical Computing. (2021).

35. Wickham, H. et al. Welcome to the Tidyverse. Journal of Open Source Software 1, 1-6 (2019).

36. Wickham, H. ggplot2: Elegant Graphics for Data Analysis. (Springer, 2016).

37. Schwinger, M. et al. Why do students use strategies that hurt their chances of academic success? A meta-analysis of antecedents of academic self-handicapping. Journal of Educational Psychology (2021)

\section{Figures}






Figure 1

The procedure of the experiment. Participants were invited to participate in a laboratory study - allegedly - in order to validate a test to measure intellectual skills among Hungarian university students. First, participants filled out a preliminary online questionnaire set (e.g., demographic data, personal importance of intelligence, implicit intelligence theory) prior to the laboratory experiment. A few days later, upon arrival to the laboratory they were randomly assigned to one of the two experimental conditions (fixed/growth intelligence mindset). Then they were provided two solvable and four unsolvable "trial" intelligence test items. This induction was supposed to generate failure expectations regarding the following "real" intelligence test. However, before the "real" test, participants were given an opportunity to self-handicap by selecting one out of seven types of music that were characterized by having enhancing, neutral or detracting effect on their test performance. Therefore, music selection represented behavioral self-handicapping. Finally, manipulation and suspicion checks were implemented. 


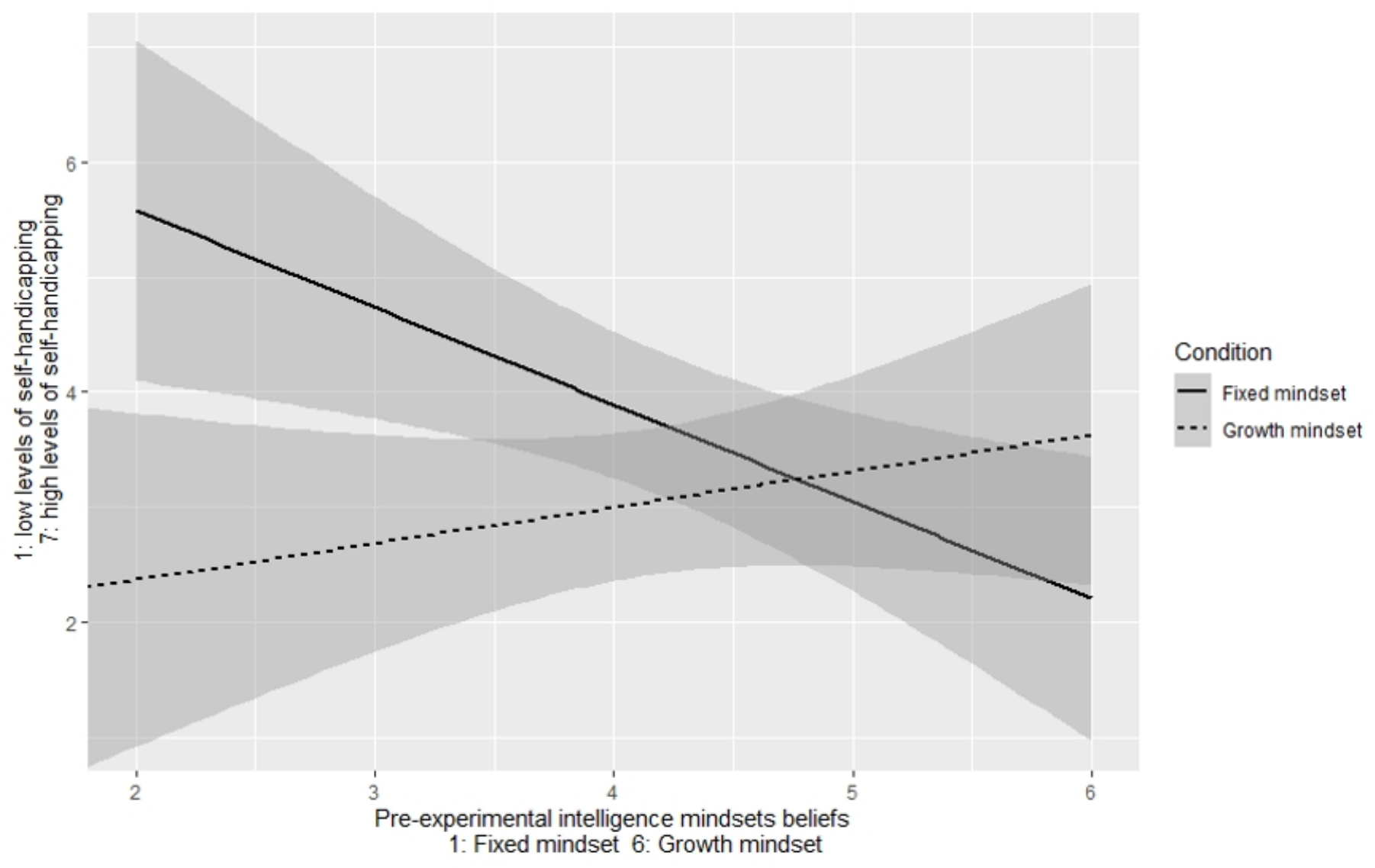

Figure 2

The interaction between prior growth intelligence mindset and intelligence mindset manipulation. The results show that a lower level of prior growth intelligence mindset made participants more vulnerable to behavioral self-handicapping, especially if they met fixed messages of intelligence. 